\title{
Hospital Surgical Volume and 3-Year Mortality in Severe Prognosis Cancers: A Population-Based Study Using Cancer Registry Data
}

Yukari Taniyama ${ }^{1,2}$, Takahiro Tabuchi ${ }^{2}$, Yuko Ohno ${ }^{1,2}$, Toshitaka Morishima ${ }^{2}$, Sumiyo Okawa ${ }^{2}$, Shihoko Koyama ${ }^{2}$, and Isao Miyashiro ${ }^{2}$

${ }^{1}$ Department of Mathematical Health Science, Graduate School of Medicine, Osaka University, Osaka, Japan

${ }^{2}$ Cancer Control Center, Osaka International Cancer Institute, Osaka, Japan

Received September 24, 2019; accepted December 15, 2019; released online January 11, 2020

\begin{abstract}
Background: The impact of hospital surgical volume on long-term mortality has not been well assessed in Japan, especially for esophageal, biliary tract, and pancreatic cancer, although these three cancers need a high level of medical-technical skill. The purpose of this study was to examine associations between hospital surgical volume and 3-year mortality for these severeprognosis cancer patients.

Methods: Patients who received curative surgery for esophageal, biliary tract, and pancreatic cancers were analyzed using the Osaka Cancer Registry data from 2006-2013. Hospital surgical volume was categorized into tertiles (high/middle/low) according to the average annual number of curative surgeries per hospital for each cancer. Three-year survivals were calculated using the Kaplan-Meier method. Hazard ratios (HRs) of 3-year mortality were calculated using Cox proportional hazard models, adjusting for patient characteristics.

Results: Three-year survival was higher with increased hospital surgical volume for all three cancers, but the relative importance of volume varied across sites. After adjustment for all confounding factors, HRs in middle- and low-volume hospitals were 1.34 (95\% confidence interval [CI], 1.14-1.58) and 1.57 (95\% CI, 1.33-1.86) for esophageal cancer; 1.39 (95\% CI, 1.15-1.67) and 1.57 (95\% CI, 1.30-1.89) for biliary tract cancer; 1.38 (95\% CI, 1.16-1.63) and 1.90 (95\% CI, 1.60-2.25) for pancreatic cancer, respectively. In particular for localized pancreatic cancer, the impact of hospital surgical volume on 3-year mortality was strong (HR 2.66; 95\% CI, 1.61-4.38).
\end{abstract}

Conclusion: We suggest that patients who require curative surgery for esophageal, biliary tract, and pancreatic cancer may benefit from referral to high-volume hospitals.

Key words: 3-year mortality; biliary tract cancer; esophageal cancer; hospital surgical volume; pancreatic cancer

Copyright $\odot 2020$ Yukari Taniyama et al. This is an open access article distributed under the terms of Creative Commons Attribution License, which permits unrestricted use, distribution, and reproduction in any medium, provided the original author and source are credited.

\section{INTRODUCTION}

It has been argued that procedural volume number per hospital for cancer surgery is an important determinant of outcomes, such as survival and mortality. ${ }^{1}$ Hospital volume is an index that indicates the total technical level of medical facilities to evaluate the effect of the levels on patient outcomes. ${ }^{2-6}$ A high level of technicalmedical skill is necessary for surgical resection, especially in severe-prognosis cancers, such as esophageal and pancreatic cancer. Previous studies have shown that the difference between high- and low-volume hospitals could be explained by the experience of the surgeons. As surgeons in high-volume hospitals have extensive experience of cancer surgery, the mortality of patients whose operations are carried out by such surgeons would decrease. ${ }^{7-10}$

In most previous studies examining hospital surgical volume, short-term mortality, such as in-hospital, within 30 days, and within 90 days, has been used as an outcome..$^{2,3,5,11}$ However, long-term mortality, such as 3- and 5-year survival, would be also important, because long-term survival represents the possibility of cure in most cancer patients.

To promote cancer control in Japan, the Japanese government instigated centralization of patients and treatments to designated cancer care hospitals, which play central roles in cancer care in Japan, but focus on five major cancers: stomach, colorectal, liver, lung, and breast cancer, which are among the most common cancers in Japan. ${ }^{12}$

In Japan, the relationship between hospital surgical volume and 5-year mortality for stomach, breast, uterus, and ovary cancer, some of which was major cancer in Japan, was reported that longterm mortality in these major cancers was high especially in verylow volume hospitals. ${ }^{13-16}$ The results suggested that cancer care for major cancers were equalized in Japan. However, information on hospital volume of other cancers, such as esophageal, biliary tract, and pancreas cancers, which have severe prognoses even at early stages, is very limited in Japan. ${ }^{17}$ Even globally, very few 


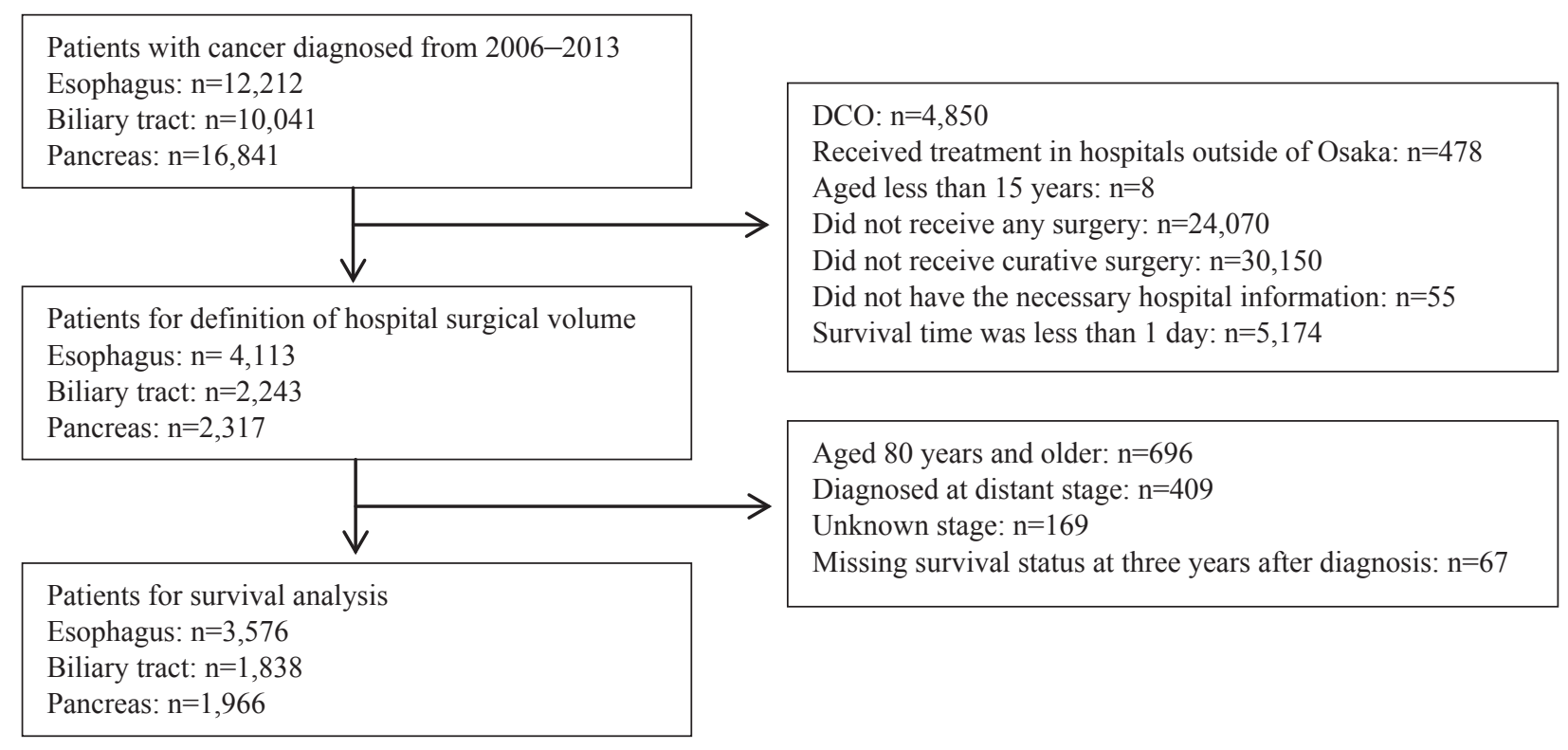

Figure 1. Flow chart for selection of patients in the Osaka Cancer Registry. DCO, death certification only.

studies have examined the relationship between hospital surgical volume and long-term mortality for biliary tract cancer. ${ }^{18}$

For esophageal, biliary tract, and pancreatic cancer patients who had surgery, prognosis was better in high-volume than in low-volume hospitals worldwide. However, adjustment factors varied in those studies, and the effect of hospital surgical volume was not defined by cancer stage. ${ }^{1-6,8-11}$

Thus, we aimed to examine the relationship between hospital surgical volume and 3-year survival for esophageal, biliary tract, and pancreatic cancer patients in Japan.

\section{METHODS}

\section{Data source and subjects}

Individual data on reported incident cases with follow-up information was retrieved from the Osaka Cancer Registry (OCR) database, a population-based cancer registry, which has been operating since December 1962 and covers the entire Osaka Prefecture, with a population of 8.8 million. ${ }^{19}$ Patient data from the OCR include sex, age at cancer diagnosis, vital status, and dates of death or the last follow-up for vital status. Tumor-specific data include cancer site, cancer stage, and date of cancer diagnosis. Treatment data include type of treatment (ie, surgery, chemotherapy, and radiation therapy), range of cancer resection, and hospital information at which patients were diagnosed and received treatment. Follow-up for vital status are routinely performed using death certificates. We identified incident cases of esophageal, biliary tract, and pancreatic cancers in the period 2006-2013, with follow-up and survival of more than 1 day. The loss to follow up was $0.4 \%$ to $0.7 \%$ for each cancer (eTable 1 ). Patients were followed up in December 2016 using official resident registries to verify vital status. Patients were treated in hospitals in Osaka, which are divided into eight medical referral regions, using relevant International Classification of Disease, $10^{\text {th }}$ Revision (ICD-10) diagnosis codes (esophageal: C15, biliary tract: C23-C24, and pancreatic: C25) for primary and multiple malignancies. The cancer stage at diagnosis was classified into the following three groups: 1) Localized: cancer is confined to the original organ: 2) Regional: cancer has spread to regional lymph nodes and/or to immediately adjacent tissues: 3) Distant: cancer has metastasized to distant organs.

Patients aged 15 through 79 undergoing curative surgery for these cancers from 2006 through 2013 were analyzed for survival rates. Patients with multiple cancers constituted $6.0 \%$ to $27.7 \%$ of patients by age and cancer site, so they were included to reduce bias due to observation period and age and improve the accuracy estimate (eTable 2). ${ }^{20,21}$ Patients whose survival status at 3 years after diagnosis was unknown, or whose cancer stage was distant or unknown, were excluded from the survival analyses (Figure 1).

The study was reviewed and approved by the Research Ethics Committee of the Osaka International Cancer Institute (no. 18-0018).

\section{Definition of hospital surgical volume}

To define the hospital surgical volume, the average annual number of curative surgeries (ie, surgery, laparoscopic, and endoscopic treatment) through 2006 through 2013 for each of esophageal, biliary tract, and pancreatic cancer was calculated based on patients aged 15 years and older at all cancer stages (localized, regional, distant, unknown). Because curative surgery has been reported as the best option for long-term mortality in cancer patients, ${ }^{22}$ the number of curative surgeries was used as a measure for hospital surgical volume. Thus, using the average annual number of surgeries, tertile categories of hospital volume (high, middle, and low) were defined.

\section{Statistical analysis}

The distribution of patient characteristics was assessed using Chi-squared tests for categorical variables. The Kaplan-Meier method and Cox proportional hazard model were used to analyze 
Table 1. Characteristics of esophageal cancer patients undergoing curative surgery at high-, middle-, and low-volume hospitals, based on data from the 2006-2013 Osaka Cancer Registry Database $(n=3,576)$

\begin{tabular}{|c|c|c|c|c|c|c|}
\hline & & & \multicolumn{3}{|c|}{ Hospital surgical volume } & \multirow[b]{2}{*}{$P$ value $^{\mathrm{a}}$} \\
\hline & & & High & Middle & Low & \\
\hline \multicolumn{7}{|l|}{ Esophagus } \\
\hline & \multirow{4}{*}{$\begin{array}{l}\text { Number of patients } \\
\text { Hospital characteristics }\end{array}$} & & 1,235 & 1,171 & 1,170 & \\
\hline & & & & & & \\
\hline & & Number of hospitals & 3 & 7 & 86 & \\
\hline & & $\begin{array}{l}\text { Procedure volume } \\
\text { (range, cases per year) }\end{array}$ & $53.3-70.1$ & $11.1-49.3$ & $0.1-10.6$ & \\
\hline & \multicolumn{6}{|l|}{ Patient characteristics, $n(\%)$} \\
\hline & \multirow[t]{6}{*}{ Age } & & & & & 0.356 \\
\hline & & $15-59$ years & 267 (21.6) & $243(20.8)$ & $234(20.0)$ & \\
\hline & & $60-64$ years & $258(20.9)$ & $232(19.8)$ & $224(19.2)$ & \\
\hline & & 65-69 years & $321(26.0)$ & $301(25.7)$ & $309(26.4)$ & \\
\hline & & $70-74$ years & $267(21.6)$ & $248(21.2)$ & $246(21.0)$ & \\
\hline & & $75-79$ years & $122(9.9)$ & $147(12.6)$ & $157(13.4)$ & \\
\hline & \multirow[t]{3}{*}{ Sex } & & & & & 0.665 \\
\hline & & Male & $1,021(82.7)$ & $982(83.9)$ & $981(83.9)$ & \\
\hline & & Female & $214(17.3)$ & $189(16.1)$ & $189(16.2)$ & \\
\hline & \multirow[t]{4}{*}{ Year of diagnosis } & & & & & $<0.001$ \\
\hline & & 2006-2008 & $330(26.7)$ & $367(31.3)$ & $344(29.4)$ & \\
\hline & & 2009-2011 & $505(40.9)$ & $456(38.9)$ & $390(33.3)$ & \\
\hline & & 2012-2013 & $400(32.4)$ & $348(29.7)$ & $436(37.3)$ & \\
\hline & \multirow[t]{3}{*}{ Stage } & & & & & $<0.001$ \\
\hline & & Localized & $699(56.6)$ & $512(43.7)$ & $600(51.3)$ & \\
\hline & & Regional & $536(43.4)$ & $659(56.3)$ & $570(48.7)$ & \\
\hline & \multirow[t]{3}{*}{ Chemotherapy } & & & & & $<0.001$ \\
\hline & & Given & $461(37.3)$ & $543(46.4)$ & $426(36.4)$ & \\
\hline & & Not given/Unknown & $774(62.7)$ & $628(53.6)$ & $744(63.6)$ & \\
\hline & \multirow[t]{3}{*}{ Radiation therapy } & & & & & $<0.001$ \\
\hline & & Given & $165(13.4)$ & $90(7.7)$ & $107(9.2)$ & \\
\hline & & Not given/Unknown & $1,070(86.6)$ & $1,081(92.3)$ & $1,063(90.9)$ & \\
\hline & \multirow[t]{3}{*}{ Residence and medical referral regions } & & & & & $<0.001$ \\
\hline & & Different & $789(63.9)$ & $315(26.9)$ & $214(18.3)$ & \\
\hline & & Same & $446(36.1)$ & $856(73.1)$ & $956(81.7)$ & \\
\hline
\end{tabular}

${ }^{\mathrm{a} C h i-s q u a r e d ~ t e s t . ~}$

survival, regardless of the cause of death. Cumulative survival for each cancer was estimated using the Kaplan-Meier method according to hospital surgical volume. Hazard ratios (HRs) and 95\% confidence intervals (CIs) were calculated using Cox proportional hazard regression models for 3-year mortality adjusting for patient characteristics. Covariates were age (15-59, 60-64, 65-69, 70-74, 75-79 years), sex (men, women), stage (localized, regional), chemotherapy (given, not given/ unknown), radiation therapy (given, not given/unknown), residence and medical referral regions (different, same) as an index of distance between residence and hospital, ${ }^{23}$ and year of diagnosis (2006-2008, 2009-2011, 2012-2013). Stratified analyses by cancer stage (localized, regional) were also conducted, as 3-year mortality might differ across cancer stages. ${ }^{24}$

Differences were considered as statistically significant if $P$ values were less than 0.05 by two-side test. We used the statistical software package STATA release 14 (Stata Corporation, College Station, TX, USA) for data management and statistical analysis.

\section{RESULTS}

Characteristics of patients with esophageal $(n=3,576)$, biliary tract $(n=1,838)$, and pancreatic cancers $(n=1,966)$ according to hospital volume category are shown in Table 1, Table 2, and Table 3, respectively. Hospital surgical volumes were defined as follows: for esophageal cancer, three high-volume hospitals with a range of 53.3 to 70.1 surgical cases per year, seven middle-volume with 11.1 to 49.3 cases, and 86 low-volume with 0.1 to 10.6 cases (Table 1); for biliary tract cancer, 10 high-volume hospitals with 7.4 to 18.0 surgical cases per year, 18 middle-volume with 3.8 to 7.3 cases, and 72 low-volume with 0.1 to 3.6 cases (Table 2); for pancreatic cancer, 5 high-volume hospitals with 13.8 to 28.4 surgical cases per year, 14 middle-volume with 4.1 to 12.8 cases, and 70 low-volume with 0.1 to 4.0 cases (Table 3 ).

Cancer stage differed by hospital surgical volume. The proportion of localized stage cancer was calculated for each of the three sites as follows: esophageal 56.6\%, 43.7\%, and 51.3\% in high-, middle-, and low-volume hospitals, respectively; biliary tract, $28.4 \%, 28.8 \%$, and $34.1 \%$, respectively; pancreatic, $20.6 \%$, $18.5 \%$, and $25.8 \%$, respectively. Patients more often go to hospitals in their home region in low-volume hospitals. By cancer site, the proportion of patients going to hospitals in their home region was as follows: esophageal, $36.1 \%, 73.1 \%$, and $81.7 \%$ in high-, middle-, and low-volume hospitals, respectively; biliary tract, $72.0 \%, 83.2 \%$, and $83.9 \%$, respectively; pancreatic, $52.9 \%$, $77.6 \%$, and $84.1 \%$, respectively.

Figure 2 shows 3-year cumulative survival curves of patients with esophageal, biliary tract, and pancreatic cancers diagnosed from 2006 through 2013 by hospital surgical volume group. Three-year survival was lower with decreasing hospital surgical 
Taniyama Y, et al.

Table 2. Characteristics of biliary tract cancer patients undergoing curative surgery at high-, middle-, and low-volume hospitals, based on data from the 2006-2013 Osaka Cancer Registry Database $(n=1,838)$

\begin{tabular}{|c|c|c|c|c|c|c|}
\hline & & & \multicolumn{3}{|c|}{ Hospital surgical volume } & \multirow[b]{2}{*}{$P$ value $^{\mathrm{a}}$} \\
\hline & & & High & Middle & Low & \\
\hline \multicolumn{7}{|l|}{ Biliary tract } \\
\hline & \multirow{4}{*}{$\begin{array}{l}\text { Number of patients } \\
\text { Hospital characteristics }\end{array}$} & & 642 & 618 & 578 & \\
\hline & & & & & & \\
\hline & & Number of hospitals & 10 & 18 & 72 & \\
\hline & & $\begin{array}{l}\text { Procedure volume } \\
\text { (range, cases per year) }\end{array}$ & $7.4-18.0$ & $3.8-7.3$ & $0.1-3.6$ & \\
\hline & \multicolumn{6}{|l|}{ Patient characteristics, $n(\%)$} \\
\hline & \multirow[t]{6}{*}{ Age } & & & & & 0.904 \\
\hline & & $15-59$ years & 94 (14.6) & $96(15.5)$ & $78(13.5)$ & \\
\hline & & $60-64$ years & $104(16.2)$ & $93(15.1)$ & $95(16.4)$ & \\
\hline & & $65-69$ years & $136(21.2)$ & $125(20.2)$ & $116(20.1)$ & \\
\hline & & $70-74$ years & $168(26.2)$ & $154(24.9)$ & $143(24.7)$ & \\
\hline & & $75-79$ years & $140(21.8)$ & $150(24.3)$ & $146(25.3)$ & \\
\hline & \multirow[t]{3}{*}{ Sex } & & & & & 0.746 \\
\hline & & Male & $379(59.0)$ & $375(60.7)$ & $339(58.7)$ & \\
\hline & & Female & $263(41.0)$ & $243(39.3)$ & $239(41.4)$ & \\
\hline & \multirow[t]{4}{*}{ Year of diagnosis } & & & & & 0.074 \\
\hline & & 2006-2008 & $187(29.1)$ & $202(32.7)$ & $169(29.2)$ & \\
\hline & & 2009-2011 & $256(39.9)$ & $238(38.5)$ & $202(35.0)$ & \\
\hline & & 2012-2013 & $199(31.0)$ & $178(28.8)$ & $207(35.8)$ & \\
\hline & \multirow[t]{3}{*}{ Stage } & & & & & 0.057 \\
\hline & & Localized & $182(28.4)$ & $178(28.8)$ & $197(34.1)$ & \\
\hline & & Regional & $460(71.7)$ & $440(71.2)$ & $381(65.9)$ & \\
\hline & \multirow[t]{3}{*}{ Chemotherapy } & & & & & 0.002 \\
\hline & & Given & $229(35.7)$ & $182(29.5)$ & $153(26.5)$ & \\
\hline & & Not given/Unknown & $413(64.3)$ & $436(70.6)$ & 425 (73.5) & \\
\hline & \multirow[t]{3}{*}{ Radiation therapy } & & & & & 0.007 \\
\hline & & Given & $18(2.8)$ & $7(1.1)$ & $4(0.7)$ & \\
\hline & & Not given/Unknown & $624(97.2)$ & $611(98.9)$ & $574(99.3)$ & \\
\hline & \multirow[t]{3}{*}{ Residence and medical referral regions } & & & & & $<0.001$ \\
\hline & & Different & $180(28.0)$ & $104(16.8)$ & $93(16.1)$ & \\
\hline & & Same & $462(72.0)$ & $514(83.2)$ & $485(83.9)$ & \\
\hline
\end{tabular}

${ }^{\mathrm{a} C h i}$-squared test.

volume for each site: esophageal, $77.6 \%, 67.3 \%$, and $65.5 \%$ in high-, middle- and low-volume hospitals, respectively; biliary tract, $67.9 \%, 58.3 \%$, and $58.0 \%$, respectively; pancreatic, $54.2 \%$, $43.7 \%$ and $34.7 \%$, respectively.

Table 4 shows HRs for 3-year mortality by hospital surgical volume. After adjustment for patient characteristics using Cox regression models, significantly higher 3-year mortality was found in middle- and low-volume hospitals compared to highvolume hospitals. HRs for esophageal cancer were 1.34 (95\% CI, $1.14-1.58)$ in middle-volume and 1.57 (95\% CI, 1.33-1.86) in low-volume hospitals; for biliary tract cancer, HRs were 1.39 (95\% CI, 1.15-1.67) in middle-volume and 1.57 (95\% CI, $1.30-1.89)$ in low-volume hospitals; and for pancreatic cancer, HRs were 1.38 (95\% CI, 1.16-1.63) in middle-volume and 1.90 (95\% CI, 1.60-2.25) in low-volume hospitals. HRs for covariate variables by site are shown as supplementary data in eTable 3 .

The results of HRs for hospital surgical volumes stratified by cancer stage are shown in Table 5. HRs for localized cases, were higher (range, 1.27 to 1.56 ) in middle-volume than high-volume hospitals, though the HRs of middle-volume hospitals were not significant in biliary tract and pancreatic cancers. In low-volume hospitals, HRs were higher (range, 1.30 to 2.66) than highvolume hospitals, and the range was wider than that in middlevolume hospitals, though the HRs of low-volume hospitals were not significant in biliary tract cancer.
HRs for regional cases were significantly higher (range, 1.33 to 1.40 ) in middle-volume than high-volume hospitals. HRs in lowvolume hospitals were also significantly higher (range, 1.58 to 1.78) than high-volume hospitals.

\section{DISCUSSION}

Increased hospital surgical volume related to lower 3-year mortality for esophageal, biliary tract, and pancreatic cancers in Osaka, after adjusting for patient characteristics. Our findings were consistent with previous studies in terms of larger risk for long-term mortality in low-volume than high-volume hospitals for these three cancers. ${ }^{4,6,8,18,25}$ Our results suggest that 3-year survival for patients with these three cancers might be improved by having curative surgery in high-volume hospitals, rather than middle- and low-volume hospitals in Osaka, Japan.

In this study, 3-year mortality was significantly different between high- and middle-volume hospitals for esophageal, biliary tract, and pancreatic cancer. Compared with middlevolume hospitals, high-volume hospitals demonstrated superior impact on patient survival. Looking at our results and those of previous studies, it appears that this tendency differs by cancer site because prevalence and level of technical-medical expertise differ by cancer site. For example, patients treated for stomach cancer, which has high prevalence in Japan, in middle-volume 
Table 3. Characteristics of pancreatic cancer patients undergoing curative surgery at high-, middle-, and low-volume hospitals, based on data from the 2006-2013 Osaka Cancer Registry Database $(n=1,966)$

\begin{tabular}{|c|c|c|c|c|c|c|}
\hline & & & \multicolumn{3}{|c|}{ Hospital surgical volume } & \multirow[b]{2}{*}{$P$ value $^{\mathrm{a}}$} \\
\hline & & & High & Middle & Low & \\
\hline \multicolumn{7}{|l|}{ Pancreas } \\
\hline & \multirow{4}{*}{$\begin{array}{l}\text { Number of patients } \\
\text { Hospital characteristics }\end{array}$} & & 684 & 666 & 616 & \\
\hline & & & & & & \\
\hline & & Number of Hospitals & 5 & 14 & 70 & \\
\hline & & $\begin{array}{l}\text { Procedure volume } \\
\text { (range, cases per year) }\end{array}$ & $13.8-28.4$ & $4.1-12.8$ & $0.1-4.0$ & \\
\hline & \multicolumn{6}{|l|}{ Patient characteristics, $n(\%)$} \\
\hline & \multirow[t]{6}{*}{ Age } & & & & & 0.014 \\
\hline & & $15-59$ years & $138(20.2)$ & $105(15.8)$ & $101(16.4)$ & \\
\hline & & $60-64$ years & $120(17.5)$ & $97(14.6)$ & $110(17.9)$ & \\
\hline & & $65-69$ years & $150(21.9)$ & $152(22.8)$ & $123(20.0)$ & \\
\hline & & $70-74$ years & $173(25.3)$ & $161(24.2)$ & $159(25.8)$ & \\
\hline & & $75-79$ years & $103(15.1)$ & $151(22.7)$ & $123(20.0)$ & \\
\hline & \multirow[t]{3}{*}{ Sex } & & & & & 0.526 \\
\hline & & Male & $388(56.7)$ & $383(57.5)$ & $368(59.7)$ & \\
\hline & & Female & $296(43.3)$ & $283(42.5)$ & $248(40.3)$ & \\
\hline & \multirow[t]{4}{*}{ Year of diagnosis } & & & & & 0.858 \\
\hline & & 2006-2008 & $205(30.0)$ & $196(29.4)$ & $176(28.6)$ & \\
\hline & & 2009-2011 & $253(37.0)$ & $234(35.1)$ & $221(35.9)$ & \\
\hline & & 2012-2013 & $226(33.0)$ & $236(35.4)$ & $219(35.6)$ & \\
\hline & \multirow[t]{3}{*}{ Stage } & & & & & 0.005 \\
\hline & & Localized & $141(20.6)$ & $123(18.5)$ & $159(25.8)$ & \\
\hline & & Regional & $543(79.4)$ & $543(81.5)$ & $457(74.2)$ & \\
\hline & \multirow[t]{3}{*}{ Chemotherapy } & & & & & 0.053 \\
\hline & & Given & $426(62.3)$ & $391(58.7)$ & $343(55.7)$ & \\
\hline & & Not given/Unknown & $258(37.7)$ & $275(41.3)$ & $273(44.3)$ & \\
\hline & \multirow[t]{3}{*}{ Radiation therapy } & & & & & $<0.001$ \\
\hline & & Given & $222(32.5)$ & $29(4.4)$ & $13(2.1)$ & \\
\hline & & Not given/Unknown & $462(67.5)$ & $637(95.7)$ & $603(97.9)$ & \\
\hline & \multirow[t]{3}{*}{ Residence and medical referral regions } & & & & & $<0.001$ \\
\hline & & Different & $322(47.1)$ & $149(22.4)$ & $98(15.9)$ & \\
\hline & & Same & $362(52.9)$ & $517(77.6)$ & $518(84.1)$ & \\
\hline
\end{tabular}

${ }^{\mathrm{a} C h i-s q u a r e d ~ t e s t . ~}$

(A)

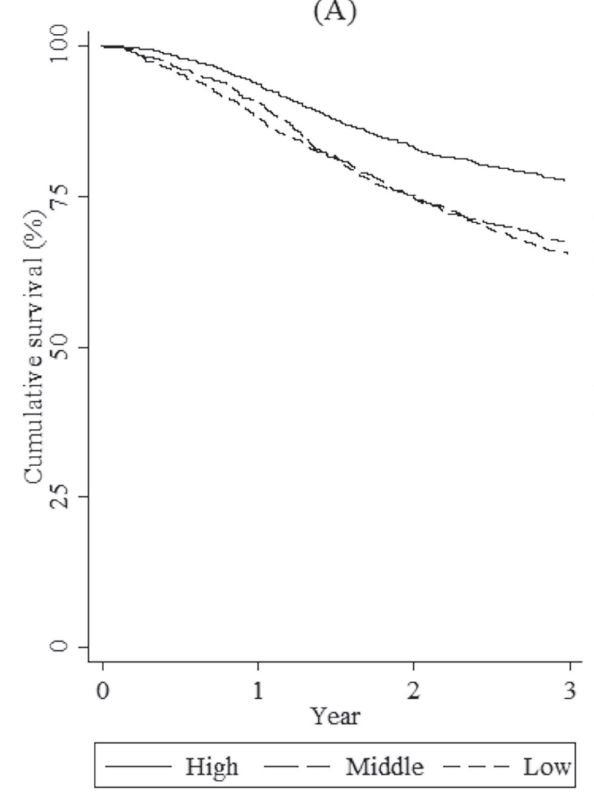

(B)

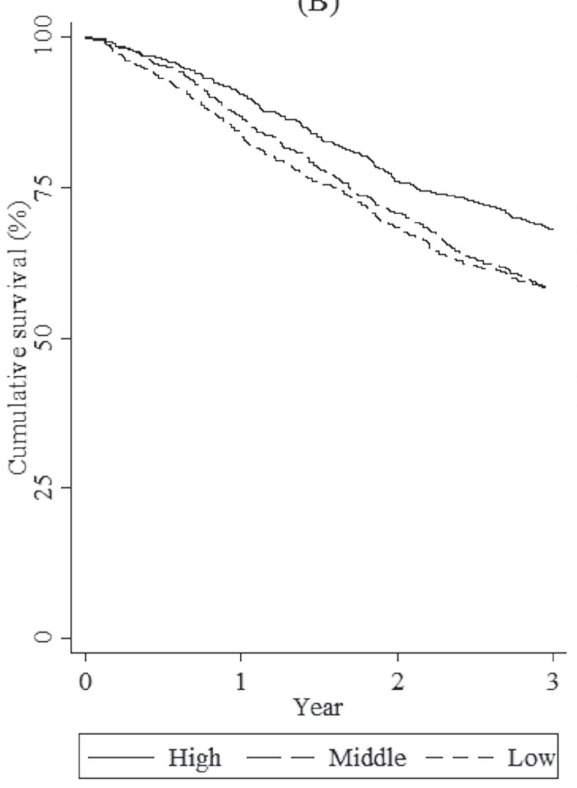

(C)

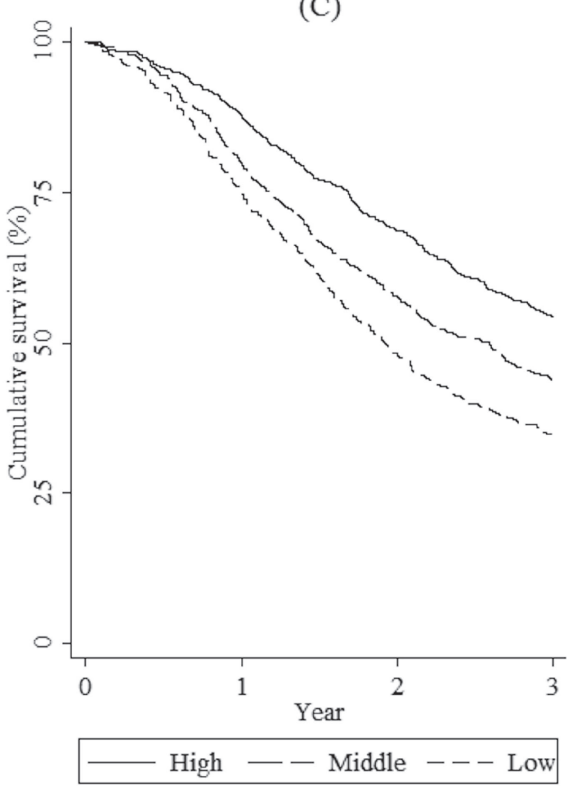

Figure 2. Kaplan-Meier estimates for 3-year survival among patients who received curative surgery for cancer at high-, middle-, and low-volume hospitals. Cancer types included are: esophagus (A), biliary tract (B), and pancreas (C).

hospitals had a similar mortality risk to those treated in highvolume hospitals. ${ }^{16,17}$ Another previous study for rectal cancer, which has high prevalence in Japan, found that survival of patients who had surgery in high-volume hospitals did not largely 
differ from that in middle- and low-volume hospitals. ${ }^{26}$ Our findings suggest that patients who need curative surgery for esophageal, biliary tract, and pancreatic cancer, which require advanced technical-medical skills, will benefit from attending high-volume rather than middle-volume hospitals.

The impact of hospital surgical volume on 3-year mortality might differ by site and cancer stage. For esophageal cancer, hospital surgical volume was significantly associated with 3-year mortality, and the associations between hospital surgical volume and 3-year mortality did not differ by cancer stage.

For localized biliary tract cancer, point estimates of HRs of middle- and low-volume hospitals to high-volume hospital were high, though they were not significant. On the other hand, for regional cases, point estimates of HRs of middle- and low-volume hospitals were significantly higher than high-volume hospitals, and higher than those for localized cases. This difference may be due to treatment difficulties, such as additional resection for invasive biliary tract cancer patients. ${ }^{27}$ Their surgeries may require higher level technical skills than localized cases, resulting in the difference in HRs by hospital surgical volume, especially in regional cases.

For pancreatic cancer, the point estimate of HR of low-volume hospitals was higher for localized than regional stage cases,

Table 4. Association between hospital surgical volume and 3year mortality in esophageal, biliary tract, and pancreatic cancer patients who received curative surgery, with and without adjustment for patient characteristics

\begin{tabular}{llcc}
\hline Site & Hospital surgical volume & Crude $\mathrm{HR}(95 \% \mathrm{CI})$ & Adjusted $\mathrm{HR}^{\mathrm{a}}(95 \% \mathrm{CI})$ \\
\hline Esophagus & & & \\
& High & 1 (reference) & 1 (reference) \\
& Middle & $1.56(1.34-1.82)$ & $1.34(1.14-1.58)$ \\
Biliary tract & Low & $1.67(1.43-1.95)$ & $1.57(1.33-1.86)$ \\
& High & 1 (reference) & 1 (reference) \\
& Middle & $1.39(1.16-1.67)$ & $1.39(1.15-1.67)$ \\
Pancreas & Low & $1.44(1.19-1.73)$ & $1.57(1.30-1.89)$ \\
& High & 1 (reference) & 1 (reference) \\
& Middle & $1.39(1.19-1.61)$ & $1.38(1.16-1.63)$ \\
& Low & $1.79(1.54-2.08)$ & $1.90(1.60-2.25)$ \\
\hline
\end{tabular}

CI, confidence interval; HR, hazard ratio.

${ }^{a}$ Adjusted for age, sex, year of diagnosis, stage, chemotherapy, radiation therapy, and residence and medical referral regions. although the $95 \%$ CIs overlapped in these cases. A previous study has reported that localized pancreatic cancer patients who received pancreaticoduodenectomy at low-volume hospitals are more likely to have margin-positive resections, and their long-term mortality is higher. ${ }^{28}$ Our results agree with this study and suggest that receiving curative surgery in low-volume hospitals is risky, especially for localized pancreatic cancer patients. The environment of hospitals providing combined modality therapy might be associated with high mortality in low-volume hospitals, because access to medical equipment for radiation therapy seems better in high-volume hospitals than in low-volume hospitals. However, we could not determine the hospital environment from the OCR database. In this study, for localized pancreatic cancer patients, the frequency of chemotherapy was higher in low-volume hospitals than in high-volume hospitals $(36.5 \%$ vs $22.0 \%$ ) and that of radiation therapy was low in both low- and high-volume hospitals $(0.0 \%$ vs $4.3 \%$ ) (eTable 4$)$. Moreover, the adjusted HR of chemotherapy was 0.82 (95\% CI, 0.56-1.22) and that of radiation therapy was 0.57 (95\% CI, 0.16-2.04); both HRs were not significant (eTable 5). These results may suggest that the high mortality in low-volume hospitals for localized pancreatic cancer patients is not associated with combined modality therapy.

Distance between residence and hospital was not associated with improved 3-year mortality for esophageal, biliary tract, and pancreatic cancer patients. Previous studies have reported that the impact of travel distance is mediated through hospital volume for biliary tract and pancreatic cancer. ${ }^{18,29}$ Although the distance was not defined using specific numerical values in our study, our results support these studies and suggest that the impact of hospital surgical volume on 3-year mortality is stronger than travel distance for esophageal, biliary tract, and pancreatic cancer patients.

This study has several limitations. First, selection bias may have occurred in this study, thus our results need to be interpreted carefully. We described the number and proportion, including patients who were excluded from the analysis (eTable 1); however, the proportion of patients who were excluded was relatively small. Furthermore, to examine the degree of the selection bias, we calculated HRs for 3-year mortality by hospital surgical volume, including patients aged 80 years and older and/ or with unknown stage (eTable 6). The results did not differ from our main results (Table 4). Therefore, the effect of excluding patients aged 80 years and older and/or with unknown stage may

Table 5. Association between hospital surgical volume and 3-year mortality in esophageal, biliary tract, and pancreatic cancer patients who received curative surgery, with and without adjustment for patient characteristics, classifying by cancer stage

\begin{tabular}{|c|c|c|c|c|c|}
\hline Cancer Stage & & Localized & & Regional & \\
\hline Site & Hospital surgical volume & Crude HR (95\% CI) & Adjusted $\mathrm{HR}^{\mathrm{a}}(95 \% \mathrm{CI})$ & Crude HR (95\% CI) & Adjusted HR $\mathrm{HR}^{\mathrm{a}}(95 \% \mathrm{CI})$ \\
\hline \multicolumn{6}{|l|}{ Esophagus } \\
\hline & High & 1 (reference) & 1 (reference) & 1 (reference) & 1 (reference) \\
\hline & Middle & $1.59(1.19-2.12)$ & $1.36(1.00-1.85)$ & $1.30(1.08-1.56)$ & $1.33(1.09-1.62)$ \\
\hline & Low & $1.65(1.25-2.18)$ & $1.47(1.09-1.98)$ & $1.59(1.32-1.91)$ & $1.60(1.30-1.96)$ \\
\hline \multicolumn{6}{|l|}{ Biliary tract } \\
\hline & High & 1 (reference) & 1 (reference) & 1 (reference) & 1 (reference) \\
\hline & Middle & $1.36(0.81-2.28)$ & $1.27(0.75-2.15)$ & $1.43(1.18-1.74)$ & $1.40(1.15-1.70)$ \\
\hline & Low & $1.50(0.91-2.47)$ & $1.30(0.77-2.17)$ & $1.57(1.28-1.92)$ & $1.58(1.29-1.93)$ \\
\hline \multicolumn{6}{|l|}{ Pancreas } \\
\hline & High & 1 (reference) & 1 (reference) & 1 (reference) & 1 (reference) \\
\hline & Middle & $1.59(0.95-2.65)$ & $1.56(0.90-2.69)$ & $1.35(1.15-1.58)$ & $1.35(1.13-1.61)$ \\
\hline & Low & $2.78(1.77-4.38)$ & $2.66(1.61-4.38)$ & $1.82(1.55-2.13)$ & $1.78(1.49-2.14)$ \\
\hline
\end{tabular}

CI, confidence interval; HR, hazard ratio.

${ }^{a}$ Adjusted for age, sex, year of diagnosis, chemotherapy, radiation therapy, and residence and medical referral regions. 
be small. Second, we did not take into account other hospital characteristics, such as the number of medical staff. ${ }^{30}$ Furthermore, we could not include some covariates, such as comorbidity and socioeconomic position. Finally, the present study is not representative of the general population in Japan because we only used data from one part of the country, Osaka.

In conclusion, the results suggest that 3-year mortality is significantly lower at high-volume hospitals compared with middle- and low-volume ones for esophageal, biliary tract, and pancreatic cancers. Our study suggests that the prognosis for patients who require curative surgery for esophageal, biliary tract, and pancreatic cancer may be improved by referral to highvolume hospitals.

\section{ACKNOWLEDGMENTS}

We would like to thank the Osaka Cancer Registry for understanding our research concept and providing data.

Funding: This study was supported by Health Labour Sciences Research Grants [grant numbers H30-Gantaisaku-Ippan-009] from the Ministry of Health, Labour and Welfare, Japan and KAKENHI Grant [grant numbers 18H03062] from Japan Society for the Promotion of Science (JSPS), Japan.

Conflicts of interest: None declared.

\section{APPENDIX A. SUPPLEMENTARY DATA}

Supplementary data related to this article can be found at https:// doi.org/10.2188/jea.JE20190242.

\section{REFERENCES}

1. Killeen SD, O’Sullivan MJ, Coffey JC, Kirwan WO, Redmond HP. Provider volume and outcomes for oncological procedures. $\mathrm{Br} J$ Surg. 2005;92:389-402.

2. Finks JF, Osborne NH, Birkmeyer JD. Trends in hospital volume and operative. N Engl J Med. 2011;364:2128-2137.

3. Gasper WJ, Glidden DV, Jin C, Way LW, Patti MG. Has recognition of the relationship between mortality rates and hospital volume for major cancer surgery in California made a difference?: a follow-up analysis of another decade. Ann Surg. 2009;250:472-483.

4. Birkmeyer JD, Sun Y, Wong SL, Stukel TA. Hospital volume and late survival after cancer surgery. Ann Surg. 2007;245:777-783.

5. Begg CB, Cramer LD, Hoskins WJ, Brennan MF. Impact of hospital volume on operative mortality for major cancer surgery. JAMA. 1998;280:1747-1751.

6. Healy MA, Yin H, Wong SL. Multimodal cancer care in poor prognosis cancers: resection drives long-term outcomes. J Surg Oncol. 2016;113:599-604.

7. Gottlieb-Vedi E, Mackenzie H, van Workum F, et al. Surgeon volume and surgeon age in relation to proficiency gain curves for prognosis following surgery for esophageal cancer. Ann Surg Oncol. 2019;26:497-505.

8. Brusselaers N, Mattsson F, Lagergren J. Hospital and surgeon volume in relation to long-term survival after oesophagectomy: systematic review and meta-analysis. Gut. 2014;63:1393-1400.

9. Derogar M, Sadr-Azodi O, Johar A, Lagergren P, Lagergren J. Hospital and surgeon volume in relation to survival after esophageal cancer surgery in a population-based study. J Clin Oncol. 2013;31: 551-557.

10. Canadian Institute for Health Information. Surgery for Pancreatic and Esophageal Cancer in Canada: Hospital Experience and Care Centralization. https://pdfs.semanticscholar.org/199f/ 4b0305137a5984785914598b5e5b700bb4d9.pdf. Accessed 16.08.19.
11. Nishigori T, Miyata H, Okabe H, et al. Impact of hospital volume on risk-adjusted mortality following oesophagectomy in Japan. $\mathrm{Br} J$ Surg. 2016;103:1880-1886.

12. Ministry of Health, Labour and Welfare, Japan. Cancer Control Measures. https://www.mhlw.go.jp/english/wp/wp-hw5/dl/ 23010222e.pdf. Accessed 16.08.19.

13. Nomura E, Tsukuma H, Ajiki W, Ishikawa O, Oshima A. Population-based study of the relationship between hospital surgical volume and 10-year survival of breast cancer patients in Osaka, Japan. Cancer Sci. 2006;97:618-622.

14. Ioka A, Tsukuma H, Ajiki W, Oshima A. Influence of hospital procedure volume on uterine cancer survival in Osaka, Japan. Cancer Sci. 2005;96:689-694.

15. Ioka A, Tsukuma H, Ajiki W, Oshima A. Influence of hospital procedure volume on ovarian cancer survival in Japan, a country with low incidence of ovarian cancer. Cancer Sci. 2004;95:233-237.

16. Nomura E, Tsukuma H, Ajiki W, Oshima A. Population-based study of relationship between hospital surgical volume and 5-year survival of stomach cancer patients in Osaka, Japan. Cancer Sci. 2003;94: 998-1002.

17. Ioka A, Tsukuma H, Ajiki W, Oshima A. Hospital procedure volume and survival of cancer patients in Osaka, Japan: a population-based study with latest cases. Jpn J Clin Oncol. 2007;37:544553.

18. Beal EW, Mehta R, Tsilimigras DI, et al. Travel to a high volume hospital to undergo resection of gallbladder cancer: does it impact quality of care and long-term outcomes? HPB. 2020;22:41-49.

19. Forman D, Bray F, Brewster DH, Gombe Mbalawa C, Kohlereds B, eds. Cancer Incidence in Five Continents Vol. X. IARC Scientific Publication No. 164. Lyon, France: International Agency for Research on Cancer; 2014.

20. Brenner H, Hakulinen T. Patients with previous cancer should not be excluded in international comparative cancer survival studies. Int J Cancer. 2007;121:2274-2278.

21. Rosso S, De Angelis R, Ciccolallo L, et al; EUROCARE Working Group. Multiple tumours in survival estimates. Eur J Cancer. 2009;45:1080-1094.

22. Groot VP, Rezaee N, Wu W, et al. Patterns, timing, and predictors of recurrence following pancreatectomy for pancreatic ductal adenocarcinoma. Ann Surg. 2018;267:936-945.

23. Shiki N, Ohno Y, Ito Y, Tsukuma H. Cancer patient survival according to patient residence and hospital place in Osaka, Japan. J Health Welfare Stat. 2010;57:28-35 (in Japanese).

24. Parkin DM, Hakulinen T. Analysis of survival. In: Jensen OM, Parkin DM, MacLennan R, Muir CS, Skeet R, eds. Cancer Registration: Principles and Methods. IARC Scientific Publications No. 95. Lyon: International Agency for Research on Cancer; 1991: 159-176.

25. Ahola R, Siiki A, Vasama K, Vornanen M, Sand J, Laukkarinen J. Effect of centralization on long-term survival after resection of pancreatic ductal adenocarcinoma. Br J Surg. 2017;104:1532-1538.

26. Jonker FHW, Hagemans JAW, Burger JWA, et al; Dutch Snapshot Research Group. The influence of hospital volume on long-term oncological outcome after rectal cancer surgery. Int J Colorectal Dis. 2017;32:1741-1747.

27. Miyazaki M, Yoshitomi H, Miyakawa S, et al. Clinical practice guidelines for the management of biliary tract cancers 2015: the 2nd English edition. J Hepatobiliary Pancreat Sci. 2015;22:510.

28. Bilimoria KY, Talamonti MS, Sener SF, et al. Effect of hospital volume on margin status after pancreaticoduodenectomy for cancer. J Am Coll Surg. 2008;207:510-519.

29. Jindal M, Zheng C, Quadri HS, et al. Why do long-distance travelers have improved pancreatectomy outcomes? J Am Coll Surg. 2017; 225:216-225

30. Yasunaga $\mathrm{H}$, Hashimoto $\mathrm{H}$, Horiguchi $\mathrm{H}$, Miyata H, Matsuda S. Variation in cancer surgical outcomes associated with physician and nurse staffing: a retrospective observational study using the Japanese diagnosis procedure combination database. BMC Health Serv Res. 2012; $12: 129$ 